\title{
Draining Sinuses Successfully Treated with a Prolonged, Partly Low-Dose Isotretinoin Treatment- A Case Report
}

\author{
Zuzana Nevoralová, MD, PhD* \\ Dermatovenereologic Department, Regional Hospital Jihlava, Vrchlického 59, 58633 Jihlava, Czech Republic \\ *Corresponding Author: Zuzana Nevoralová, Dermatovenereologic Department, Regional Hospital \\ Jihlava, Vrchlického 59, 58633 Jihlava, Czech Republic, Email: nevoralovaz@nemji.cz.
}

\begin{abstract}
The draining sinus is the most disturbing acne lesion. It is a lesion featuring the combination of nodules and scars. Typically, this inflammatory tunnel develops in the face, especially in the nasolabial folds, cheeks, bridge of the nose, chin, and sides of the neck. Treatment is very difficult. In most cases, only surgical excision of the entire lesion provides a final cure. A 25 year-old man with draining sinuses in nasolabial folds is reported. The therapeutic regimen included a prolonged, partly low-dose isotretinoin treatment, in the beginning in the combination with oral corticosteroid. Outcome was favorable, with no recurrences during 12 months of the treatment and during the following 3 months.
\end{abstract}

Keywords: Draining sinuses, Treatment, Low dose, Oral isotretinoin

\section{INTRODUCTION}

The draining sinus is the most disturbing lesion of acne repertoire. Typically, this inflammatory tunnel develops in the face, especially in the nasolabial folds, cheeks, bridge of the nose, chin, and sides of the neck. Treatment is very difficult. In most cases, only surgical excision of the entire lesion provides a final cure. A 25 year-old man with draining sinuses in nasolabial folds is reported. The draining sinus is described in detail and special aspects of the case are pointed out.

\section{THE CASE REPORT}

A 25 year-old man was sent to our Acne Clinic because of worsening acne on his face. His problems lasted for about 2 years already, no effective treatment was given to him yet. He was very distressful with his appearance. The patient did not have any health problems in the childhood, he had no medication. He reported an allergy to penicillin. No family history of sinus tracts or acne was remarkable. The patient worked as a driver and lived with his family.

Objective finding at the introductory examination (fig 1): On the face in nasolabial folds longitudinal rose to red infiltrates approximately 10 centimetres at length and till 10 millimetres at diameter left and till 15 millimetres at diameter right, partly fluctuant, were recognisable. No other signs of acne were present. A diagnosis of sinus tracts was established. The patient was informed about the diagnosis and possibilities of the treatment were explained to him. Because of he consistently refused any invasive therapy- an oral treatment with isotretinoin and corticosteroid and additional local therapy were chosen. The patient was completely informed about isotretinoin treatment. Laboratory was done- no pathology was found. The treatment with oral isotretinoin was started with an initial dose $20 \mathrm{mg} /$ day $(0,3$ $\mathrm{mg} / \mathrm{kg} /$ day). Methylprednisolon at the dose of $20 \mathrm{mg}$ was added. Local ichtoxyl and later combination gentamycin- bethamethason was recommended. After 3 weeks the dose of oral isotretinoin was increased to $30 \mathrm{mg} /$ day $(0,45$ $\mathrm{mg} / \mathrm{kg} /$ day). The dose of methylprednisolon was slowly reduced, the treatment was stopped after 7 weeks. Further controls continued in regular intervals of one month. Clinical stage of sinuses and side effects of oral isotretinoin treatment (including laboratory) were followed. After 2 months of isotretinoin treatment redness of sinuses disappeared, a size of sinuses and their fluctuation were slowly reduced during next 8 months. After 10 months (fig 2) a low dose of isotretinoin $(10 \mathrm{mg}, 0,15 \mathrm{mg} / \mathrm{kg} / \mathrm{day})$ was started, after 12 months (fig 3) only $10 \mathrm{mg}$ every other day $(0,075 \mathrm{mg} / \mathrm{kg} / \mathrm{day})$ was given for 12 months. Only common side effects of isotretinoin were observed: cheilitis, dryness and redness of skin. Active clinical symptoms except exceptional minimal serous secretion have not 
returned during the low-dose isotretinoin treatment (fig 4). Since the finishing of the isotretinoin treatment (for 3 months by now) the activity of sinus tracts has still been at the minimum. The patient is very satisfied with his appearance.

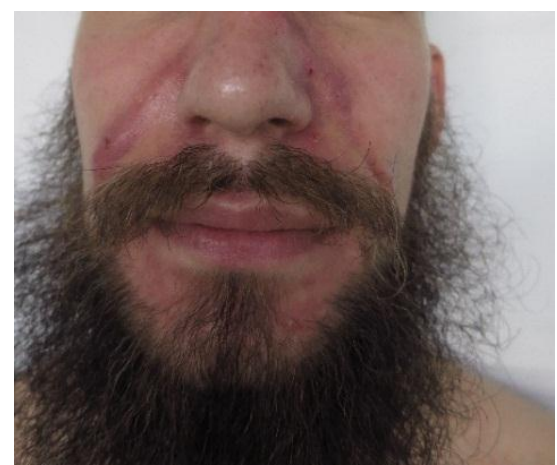

Fig1

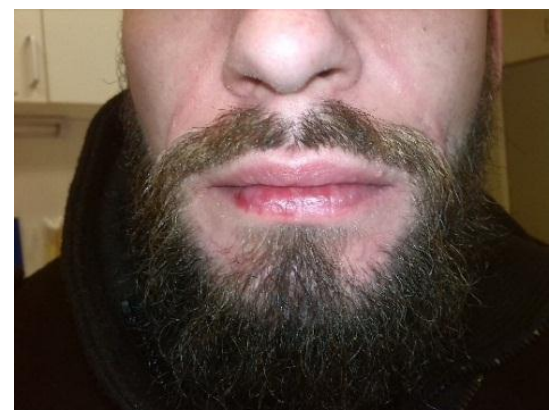

Fig2

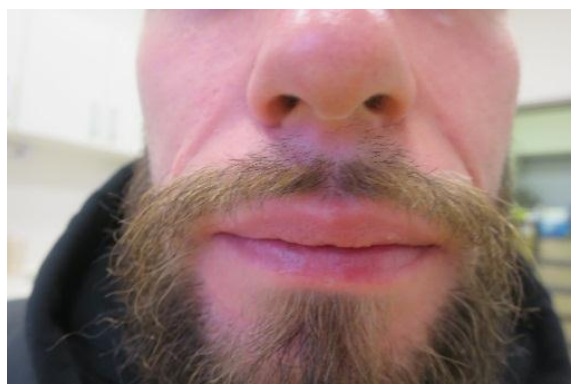

Fig3

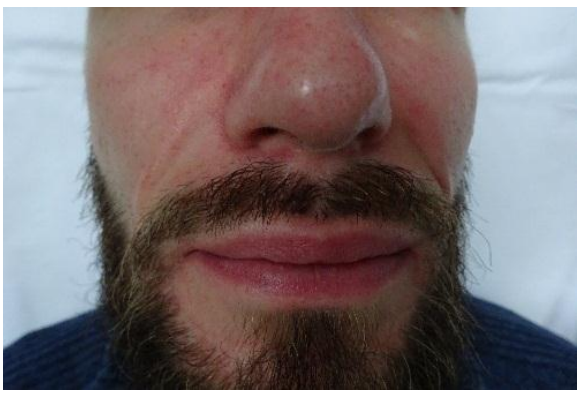

Fig4

\section{DISCUSSION}

The draining sinus is the most disturbing acne lesion. It is a lesion featuring the combination of nodules and scars. Typically, these inflammatory tunnels develops in the face, especially in the nasolabial folds, cheeks, bridge of the nose, chin, and sides of the neck (1). Clinically, it is an elongated $(2-5 \mathrm{~cm}$ long), elevated, periodically inflamed lesion, which sporadically discharges pus. The lesion persists with no tendency to spontaneous regression. (2) It periodically drains and crusts. The draining sinus is entirely analogous to the pilonidal cyst of the coccygeal area. It can grow slowly for years, intermittently calming down and later draining again. Spontaneous healing hardly ever occurs. (1) Draining sinuses are very often misdiagnosed, resulting in inappropriate surgical intervention. While draining nodules and nodules inevitably leave a scar, incisions produce far worse scarring. Treatment of draining sinus is very difficult. It is done conservatively with aspiration of hemorrhagic contents and injection of a corticosteroid crystal suspension with tightly fitting compression bandages worn for several days thereafter. (1) Sometimes cryosurgery can be effective. (2) Oral corticosteroids can also be tried for several weeks. (1) Oral antibiotics are effective, only if secondary infection is present, which happens only seldom (3). Isotretinoin provides only temporary and inconsistent relief. (1) It can help probably thanks to his antiinflammatory effect. According to some authors (3) a treatment should be started with a low dose $(0,5 \mathrm{mg} / \mathrm{kg} /$ day $)$ to prevent a granulation tissue creation. A therapy should be stopped only at a cumulative dose of 120 - 150 $\mathrm{mg} / \mathrm{kg}$. Unfortunately, after stopping isotretinoin treatment a relapse can happen. (3). In the most cases, only surgical excision of the entire lesion provides a final cure. $(1,2,4)$.

Our patient suffered from typical draining sinuses in nasolabial folds. But the diagnosis was recognized only after 2 years of duration in our Acne Clinic. At that time, the patient was very distressful with his appearance. In the literature, we found only one case report of draining sinus treated without surgical intervention (4). The therapeutic regimen included intralesional corticosteroid injection, systemic corticosteroids along with a macrolide antibiotic, and systemic isotretinoin with an excellent effect. Our treatment possibilities were reduced with patient's refusing any invasive therapy. That is why an oral treatment with isotretinoin in the beginning in combination with corticosteroid was chosen. First an usual dose of $0,5 \mathrm{mg} / \mathrm{kg} /$ day (till $135 \mathrm{mg} / \mathrm{kg}$ ), later a very low-dose (total $60 \mathrm{mg} / \mathrm{kg}$ ) to prevent a relapse often happening after stopping isotretinoin treatment. Until 
inflammation and secretion were stopped, an additional local therapy was added. Outcome was favorable, with no recurrences during 12 months of treatment and during the following 3 months.

\section{CONClusion}

The draining sinus is the most disturbing lesion of acne repertoire. All dermatovenerologists should consider this diagnosis in patients with suspicious signs. Treatment is very difficult. In most cases, only surgical excision of the entire lesion provides a final cure. If a patient consistently refuses any invasive therapy, a therapeutic regimen including a prolonged, partly low-dose isotretinoin treatment to prevent a relapse can be tried.

\section{REFERENCES}

[1] Plewig G, Kligman AM, Acne and rosacea, Berlin Heidelberg, Springer-Verlag, 2000, pp. 120-151, 196-197, 234.

[2] Jansen T, Lindner A, Plewig G, Draining sinus in acne and rosacea. A clinical, histopathologic and experimental study, Hautarzt 46(6), 1995, pp. 417-420.

[3] Leyden JJ, Oral isotretinoin. How Can We Treat Difficult Acne Patients? Dermatology, 1997, 195 (suppl 1), pp. 29-33.

[4] Jansen T, Romiti R, Plewig G, Altmeyer , Disfiguring Draining Sinus Tracts in a Female Acne Patient, Pediatric Dermatology 17(2), 2000, pp. 123-5.

Citation: Zuzana Nevoralová. Draining Sinuses Successfully Treated with a Prolonged, Partly Low-Dose Isotretinoin Treatment- A Case Report. ARC Journal of Clinical Case Reports. 2018; 4(1): 8-10. doi:dx.doi.org/ 10.20431/2455-9806.0401003.

Copyright: (C) 2018 Authors. This is an open-access article distributed under the terms of the Creative Commons Attribution License, which permits unrestricted use, distribution, and reproduction in any medium, provided the original author and source are credited. 